\title{
Correlation between Radiological Parameters and Functional Outcome of Healed Unstable Fracture Distal Radius after External Fixation
}

\author{
Robin Shrestha, ${ }^{1}$ Hemant Gupta, ${ }^{1}$ Manoj Kandel $^{1}$ \\ ${ }^{1}$ Department of Orthopaedics, College of Medical Sciences Bharatpur, Chitwan.
}

\begin{abstract}
Background: Wrist fractures represent about one-sixth of all fractures seen in emergency department. The goal of treating such fractures is no longer only fracture union, but also the restoration of normal anatomy with early functional recovery, as well as full and painless motion of the wrist. In this prospective study we intend to evaluate the correlation between functional outcome and radiological parameters of the unstable fracture of the distal radius when treated with external fixator. Methods: A hospital based, observational study was conducted at department of Orthopedics, College of Medical Sciences Teaching Hospital, Bharatpur, Chitwan, during the period of January 2011 to November 2013, 54 patients, 33 male and 21 female, with unstable fracture of the distal end of radius were treated with external fixator and followed for a period of 18 weeks. Results: The clinical and radiological outcome were evaluated on the basis of modification, by Sarmiento et al., of the Demerit Point system of Gartland and Werley and Sarmiento et al's modification of Lidstrom's scoring system respectively at the end of 18 weeks. The clinical result was excellent in 25 cases, good in 19 cases and fair in eight cases. There were $8(15.4 \%)$ excellent, $25(48.1 \%)$ good, $15(28.8 \%)$ fair and $4(7.7 \%)$ poor cases according to radiological scoring. Conclusions: In this study we found no correlation between clinical outcome and radiological parameters following external fixation in distal radius fractures.
\end{abstract}

Keywords: demerit point system; external fixator; fracture distal radius; lidstrom's scoring system.

\section{INTRODUCTION}

External skeletal fixation for the treatment of displaced, unstable fractures of the distal radius is a minimally invasive procedure with reduction by ligamentotaxis. The use of external fixator in the management of these fractures not only give improved results both functionally and anatomically but also provide grip strength and endurance by restoring length and alignment of the fracture fragments. It is assumed that in distal radius fracture, a good result will be achieved irrespective of the appearance of the reduction. This holds true in elderly and low demand patients, but in those with higher demands preserving the integrity of wrist joint and maintain motion of the hand is important. $^{1,2}$ Restoration of congruity of the articular surface is the most critical factor for a good functional result. The importance of restoration of radiological parameters for good functional outcome in treatment of intra-articular fractures of distal end of radius has been advocated by many orthopedists. ${ }^{4-6}$ Inability to achieve near anatomic reduction can lead to degenerative arthritis, distal radio-ulnar and mid-carpal instability, and ulnar impaction syndrome resulting in pain, decreased motion and strength. However, other authors concluded that it was difficult to demonstrate conclusively that the reduction of the displaced fracture fragments reduced the rate of posttraumatic osteoarthritis and that they led to improved clinical results and also despite the progression of arthrosis, patients showed a high level of function suggesting no statistical correlation between the functional outcome and radiological parameters. ${ }^{7,8}$ Whether or not acceptable radiological reduction leads to better clinical outcome, striving for an anatomic reduction of the articular surface is accepted as a desirable goal.

\section{METHODS}

This was a hospital based observational study conducted at College of Medical Sciences Teaching Hospital Bharatpur, Chitwan from January 2011 to November 2013. Fifty- four patients with fracture

Correspondence: Dr. Robin Shrestha, Department of Orthopedics, College of Medical Sciences Bharatpur, Chitwan

Email: dr.robinshrestha@gmail.com. Phone: +977-9855054611. DOI:10.3126/jcmsn.v15i2.21127. Article Received:.2018-09-21. Article accepted: 2019-02-19. 
Shrestha et al. Correlation Between Radiological Parameters and Functional Outcome of..

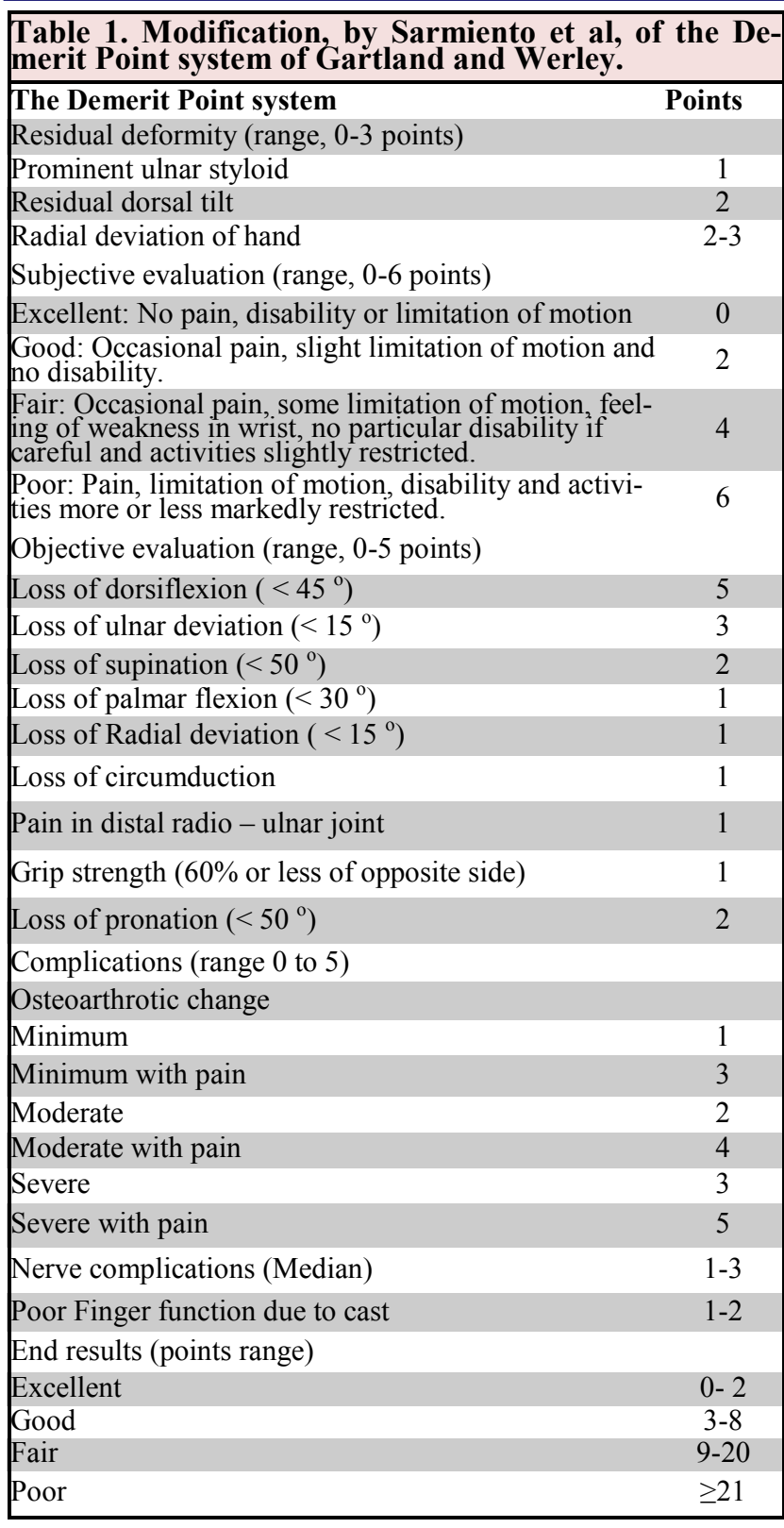

of distal radius satisfying the following criteria were treated with external fixator and included in the study:

1. dorsal angulation of more than 20 degrees

2. a loss of radial length of more than 10 millimeters

3. intra articular extension

4. severe dorsal metaphyseal comminution

Patients were operated under brachial plexus block and general anesthesia when brachial block failed. Tourniquet was not used for the surgery. Under fluoroscopic guidance closed reduction was done. Two schanz pins on each sides of the fracture were applied and connected with a pair of AO rods. Supplemental K wires were not used for the fixation of fractures. Range of movement of fingers and grip exercises were initiated from the next day of surgery in all the cases. The external fixators were removed at $6^{\text {th }}$ week and subjective and objective evaluation of functional status was evaluated by
Table 2. Sarmiento et al's modification of Lidstrom's scoring.

\begin{tabular}{|llll|}
\hline $\begin{array}{l}\text { Dorsal } \\
\text { Angle } \\
\left({ }^{\circ}\right)\end{array}$ & $\begin{array}{l}\text { Loss of Radial } \\
\text { Length }(\mathbf{m m})\end{array}$ & $\begin{array}{l}\text { Loss of } \\
\text { Radial Tilt } \\
\left({ }^{\circ}\right)\end{array}$ & $\begin{array}{l}\text { Score for } \\
\text { Each Meas- } \\
\text { urement }\end{array}$ \\
Neutral & $<3$ & 0 to 4 & 0 \\
1 to 10 & 3 to 6 & 5 to 9 & 1 \\
11 to 14 & 7 to 11 & 10 to 14 & 2 \\
$\geq 15$ & $>12$ & $>15$ & 4 \\
\hline
\end{tabular}

using Modification, by Sarmiento et al, ${ }^{9}$ of the Demerit Point system of Gartland and Werley ${ }^{10}$ (Table 1) and radiological result by Sarmiento et al's modification of Lidstrom's scoring (Table 2) at $18^{\text {th }}$ week.

\section{RESULTS}

Out of 54 patients, 52 were followed up for 18 weeks while two patients were lost to follow up after 6 weeks. In the present study, mean age was $34.94 \pm 9.06$ years and maximum incidence occurred between 31 to 40 years $(38.9 \%)$. There were 33 males $(61.1 \%)$ and 21 females $(38.9 \%)$ and the female to male ratio was 1:1.57. The time from injury to operation ranged from zero to eight days (average 1.61 \pm 1.25 days). In our study, the major cause of fracture was motor vehicle accidents $(57.4 \%)$ and fall from a height $(27.8 \%)$. Out of 54 distal radius fractures, 24 (44.4\%) were of the right side and $30(55.6 \%)$ were of the left side. The most common type of fracture according to AO/ASIF classification was Type C1 (50\%) which was followed by Type C2 (25.9\%) and Type C3 (18.5\%). Three patients (5.6\%) developed pin tract infection, three patients felt $(5.6 \%)$ paraesthesia in the dorsum of thumb and index finger, four patients $(7.4 \%)$ complained of puckering of the skin at the site of insertion of schanz pins and one $(1.9 \%)$ patient had stiffness of the ipsilateral elbow. All the range of movements was measured with the help of goniometer at the end of 18 weeks. In 39 cases (75\%) more than 45 degrees of dorsiflexion was possible. Palmar flexion more than 30 degrees was possible in $100 \%$ of the cases. Ulnar deviation of more than 15 degrees was present in 44 cases $(84.6 \%)$. Radial deviation was less than 15 degrees in only four cases $(7.7 \%)$. Supination was found to be more than 50 degree in 41 cases $(78.8 \%)$ while less than 50 degrees in 11 cases $(21.2 \%)$. Pronation was measured to be more than 50 degrees in 46 cases $(88.5 \%)$ and less than 50 degrees in six cases $(11.5 \%)$. Also circumduction of the wrist was possible in 36 patients $(69.2 \%)$ and not possible in the other 16 patients $(30.8 \%)$. All the measurements were done in posteroanterior and lateral radiographs of distal radius with the help of a ruler and a goniometer. Radial 
Shrestha et al. Correlation Between Radiological Parameters and Functional Outcome of..

inclination was found to be in the range of 23-18 degree in 43 cases, 17-13 degree in seven cases and 12-10 degree in two cases. Radial height was equal to or less than $6 \mathrm{~mm}$ in six cases $(11.5 \%)$. Only one patient had ulnar variance of more than $2 \mathrm{~mm}$ while the remaining 51 patients had it in the range of -2 to $2 \mathrm{~mm}$. There was volar tilt up to 11 degree in 37 cases $(71.2 \%)$ while dorsal tilt was found in 15 cases $(28.8 \%)$. Articular step-off of more than $2 \mathrm{~mm}$ was present in only two cases $(3.8 \%)$. There were $8(15.4 \%)$ excellent, 25 (48.1\%) good, $15(28.8 \%)$ fair and $4(7.7 \%)$ poor cases according to radiological scoring. The clinical result was excellent in $25(48.1 \%)$ cases, good in $19(36.5 \%)$ cases and fair in eight $(15.4 \%)$ cases. Out of 25 cases with excellent functional outcome only 8 had radiologically excellent score and even out of 19 radiologically poor or fair cases 14 had excellent or good functional outcome (Table 3). found that the satisfactory functional results were obtained, despite unsatisfactory radiological results in the older age group. ${ }^{18}$ In a prospective study conducted by Ranjeet $\mathrm{N}$ and Estrella EP, they could not find any correlation of an acceptable reduction to a better functional outcome. They did not find a particular variable that was associated with either a good or a bad functional outcome. ${ }^{7}$

Knirk and Jupiter, in a clinical study on patients with intra-articular distal radius fractures less than forty years old, found that the prevalence of osteoarthritis and a poor functional outcome at a mean of 6.7 years after the injury was higher for the fractures which healed with an incongruous radio-carpal joint, than for those which healed with a congruous joint. ${ }^{5}$ Chung et al., in their study did not find any relationship between the potential predictors such as hand dominance, gender, AO

Table 3. Correlation between functional outcome and radiological parameters.

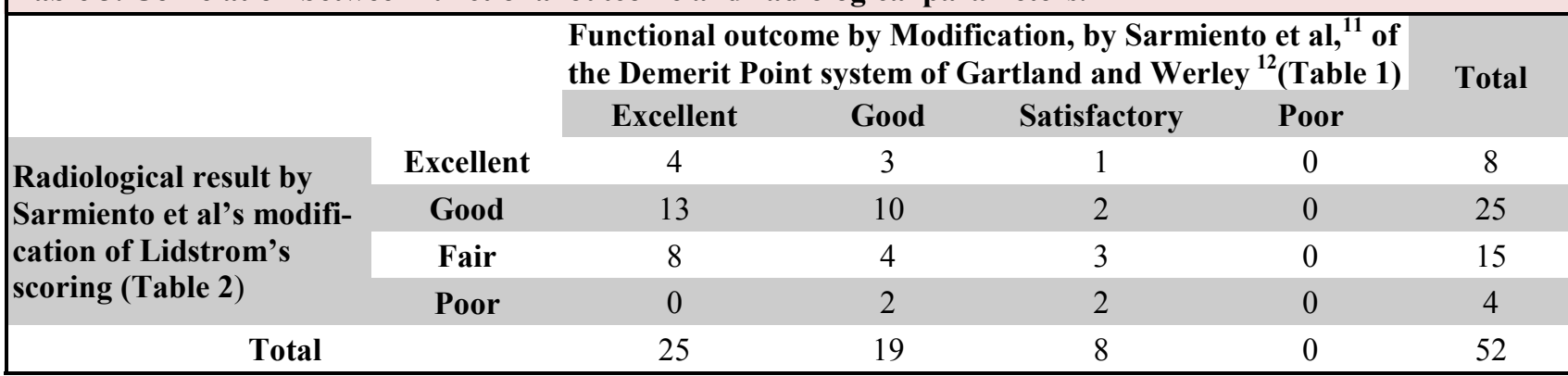

\section{DISCUSSION}

Fractures of the distal radius represent approximately $15 \%$ of all fractures treated by orthopaedic surgeons. ${ }^{13}$ Fractures of the distal aspect of the radius with intra- articular involvement and comminution continue to pose therapeutic challenge. Unstable distal radius fractures are difficult to reduce anatomically and are associated with high prevalence of complications. If these fractures are allowed to collapse, radial shortening, angulation, and articular incongruity may cause permanent deformity and loss of function. ${ }^{14}$

A lot of surgeons advocate external fixator as it is inexpensive, patient compliant, causes less morbidity, decreases the hospital stay and also its removal can be done without the need of anesthesia. Various studies have indicated that it not only gives a good functional result and patient satisfaction but also allows near normal anatomic restoration. ${ }^{15-17}$ Kumar $\mathrm{S}$ et al. concluded that the restoration of anatomical radial tilt resulted in better functional outcome in young patients. They fracture classification, radial height, radial inclination, complications, ulnar styloid fracture and ulnar variance, which were identified in the literature as the important factors which influenced the outcomes after intraarticular distal radius fracture. ${ }^{8}$

In our study all the cases of pin site infections were eradicated with regular pin site dressing with hydrogen peroxide and a course of antibiotics without any sequelae. Paraesthesias in all three patients gradually improved after few weeks without any specific treatment. The patient who complained of stiffness of elbow also regained near normal range of motion by the end of 18 weeks with appropriate physiotherapy. The cause of stiffness in that case was attributed to immobilization of the ipsilateral elbow in an above elbow posterior slab following its posterior dislocation. There were no cases of reflex sympathetic dystrophy, rupture of extensor pollicis tendon or pin loosening. We found that excellent functional outcome did not depend upon excellent radiological parameters. Even cases with poor or fair radiological score had excellent functional outcome. Hence, the functional and radiological outcome did not correlate with each other. 
Shrestha et al. Correlation Between Radiological Parameters and Functional Outcome of..

\section{CONCLUSIONS}

We consider external fixator to be an excellent method of treating unstable distal radius fracture due to its ability to maintain radial inclination, radial height and volar tilt without opening the fracture site. In our study, we could not find any correlation between radiological parameters according to Sarmiento et al's modification of Lidstrom's scoring and functional outcome according to Modification, by Sarmiento et al, of the Demerit Point system of Gartland and Werley.

supination. J Bone and Joint Surg. 1975;57:31117

10.Gartland JJ, Werley CW. Evaluation of healed Colle's fractures. J Bone and Joint Surg. 1951;33:895-907.

11.Sarmiento A, Pratt GW, Berry NC, Sinclair WF. Colle's fractures. Functional bracing in supination. J Bone and Joint Surg. 1975;57:31117.

12.Gartland JJ, Werley CW. Evaluation of healed Colle's fractures. J Bone and Joint Surg. 1951;33:895-907.

13. Arora S, Grover SB, Batra S, Sharma VK. Comparative evaluation of postreduction intraarticular distal radial fractures by radiographs and multidetector computed tomography. J Bone Joint Surg Am. 2010;92:2523-32.

14.Edwards GS. Intra-articular fractures of the distal part of the radius treated with the small AO external fixator. J Bone Joint Surg Am. 1991;73:1241-50.

15. Haus BM, Jupiter JB. Intra-articular fractures of the distal end of the radius in young adults: Reexamined as evidence based and outcome medicine. J Bone Joint Surg Am.2009;91:298491.

16.Boparai R, Boparai RS, Kapila R, Pandher DS. Role of ligamentotaxis in management of comminuted intra/juxta articular fractures. Indian J Orthop. 2006;40:185-7.

17.Clyburn TA. Dynamic external fixation for comminuted intra-articular fractures of the distal end of the radius. J Bone Joint Surg Am. 1987;69:248-54.

18.Kumar S, Penematsa S, Sadri M, Deshmukh SC. Can radiological results be surrogate markers of functional outcome in distal radial extra-articular fractures? Int Orthop. 2008;32 (4):505-9.

Citation: Shrestha R, Gupta H, Kandel M. Correlation Between Radiological Parameters and Functional Outcome of Healed Unstable Fracture Distal Radius after External Fixation. JCMS Nepal. 2019; 15(2):103-6. 